\title{
СПОСОБ КОЛИЧЕСТВЕННОЙ ОЦЕНКИ ВИРУСНОЙ НАГРУЗКИ В КЛИНИЧЕСКИХ ОБРАЗЦАХ
}

\section{METHOD FOR QUANTIFYING THE CONTENT OF INTESTINAL VIRUSES IN CLINICAL SAMPLES}

\section{A. Kashnikov}

Summary. In the study of intestinal viruses, there is often a need for an absolute quantitative assessment of the viral load (VN). The determination of the number of virus units in a sample is possible only using methods based on the application of standards identical to the test sample. Transmission electron microscopy (TEM) is not the most accurate but effective method of quantitative analysis of HV. This method is based on the use of live viral culture (VVC) $\nabla$ the most adequate of the existing international standards for the quantitative determination of VN. In recent years, the absolute version of real-time PCR (PCR-RV) has been preferred in the quantitative analysis of HV. However, this method is no less timeconsuming than TEM and the relative version of real-time PCR. In this paper, we propose a simplified method for quantifying the content of a specific type of virus in a clinical sample. Its essence is to determine the units of viruses of this type present in the sample under study, according to a standard schedule constructed using samples taken as a standard, in relation to this type of virus. The method is based on the use of data obtained by a relative variant of $P C R-R V$, on the presence of a specific virus in the sample and its quantitative ratio to viruses of another type. This information can also be confirmed using the TEM technique. As a working method for obtaining quantitative data on HV in the methodology, using a standard graph, a simple-to-perform technique of NanoDrop spectrophotometry is proposed. This technique makes it possible to determine the $\mathrm{HV}$ in a pre-purified and concentrated virus-containing material by the concentration of nucleic acid (NC) isolated from the purified virus, which is quantitatively comparable to the virus content in the sample. The graphical method will allow to determine the HV in clinical samples with one or more types of viruses, separately for each type. The reliability of the information on the value of the HV calculated by the proposed method is confirmed by the quantitative data obtained using TEM. It will significantly simplify the quantitative analysis of HV in samples with the ability to determine the number of viral particles only on the basis of data on the concentration of viral genetic material obtained by NanoDrop spectrophotometry. Using the graphical method, it will be possible to determine the amount of virus in samples from 108 particles/ml and higher, and with a preliminary concentration-and with a lower concentration.

Keywords: transmission electron microscopy, viral nucleic acid, NanoDrop spectrophotometry, real-time $P C R$, threshold cycle, standard curve.
Кашников Александр Юрьевич

Н.с., ФБУН «Нижегородский научноисследовательский институт эпидемиологии и микробиологии им. академика И.Н. Блохиной» РоспотребнадзораРФ a.kashn@yandex.ru

Аннотация. При исследовании кишечных вирусов часто возникает необходимость абсолютной количественной оценки вирусной нагрузки (ВН). Определение количества единиц вируса в пробе возможно только с использованием методов, в основе которых лежит применение стандартов, идентичных исследуемому образцу. Не самым точным, но эффективным методом количественного анализа ВН является трансмиссионная электронная микроскопия (ТЭМ). Этот метод основан на использовании живой вирусной культуры (ЖВК) \ наиболее адекватного из существующих международных стандартов для количественного определения ВН. В последние годы в количественном анализе ВН предпочтение отдается абсолютному варианту ПЦР в реальном времени (ПЦР-РВ). Однако, данный метод не менее трудоемок, чем ТЭМ и относительный вариант ПЦР в реальном времени. В данной работе предлагается упрощенный способ количественной оценки ВН в клинических образцах. Суть его сводится к количественному определению ВН по стандартному графику, построенному по данным, полученным с использованием наиболее простой в исполнении техники NanoDrop-спектрофотометрии. Данный способ позволяет определить ВН в предварительно очищенном и сконцентрированном вирусосодержащем образце по концентрации выделенной нуклеиновой кислоты (НК), которая примерно сопоставима количественно с содержанием вируса в пробе. В предлагаемом способе используется информация о вирусах, присутствующих в клиническом образце, полученная относительным вариантом ПЦР. Стандартом для построения калибровочного графика служит одна из клинических проб с высокой концентрацией вирусных частиц. Достоверность информации о величине ВН, вычисленной предлагаемым методом, подтверждена количественными данными, полученными с помощью ТЭМ. Графический метод позволит определять ВН в клинических образцах с одним или несколькими видами вирусов, отдельно для каждого вида. Он существенно упростит количественный анализ ВН в образцах с возможностью определения числа вирусных частиц только на основе данных о концентрации вирусного генетического материала, полученных методом NanoDrop-спектрофотометрии. С помощью графического способа можно будет определять количество вируса в пробах от 108 частиц/мл и выше, а при предварительном концентрировании - и с меньшей концентрацией.

Ключевые слова: вирусная нагрузка, нуклеиновая кислота, ПЦР в реальном времени, NanoDrop-спектрофотометрия, градуировочная кривая, трансмиссионная электронная микроскопия, латексные частицы. 


\section{Введение}

$\Pi$ ри исследовании образцов, содержащих вирусы, неизбежно встает вопрос определения количества вирусных частиц в пробе - вирусной нагрузки (ВН). Необходимость измерения ВН возникает не только в случаях, когда требуется информация о концентрации инфекционных частиц в клиническом образце, но и в тех случаях, когда важно знать количество всех частиц, В том числе неинфекционных, которые также могут влиять на иммунный ответ хозяина, например, при разработке вакцин [3, с 337-342]. Абсолютный количественный анализ ВН требует применения международных количественных стандартов, самыми адекватными из которых считаются образцы в виде живой вирусной культуры (ЖВК). Известно несколько способов абсолютного количественного анализа вирусной нагрузки (ВН). Наиболее известными, позволяющими осуществить количественное определение вирусных частиц в препарате, являются трансмиссионная (просвечивающая) электронная микроскопия (ТЭМ) и абсолютный вариант полимеразной цепной реакция в реальном времени (ПЦР-PB) «Real-time PCR». В этих методах ВН в анализируемой пробе сравнивают с международным стандартом, в качестве которого используют образец с известным числом вирусных единиц. Такие количественные стандарты в виде ЖВК получены с помощью техники ТЭМ. Однако, эти методы количественного анализа ВН являются трудоемкими и дорогостоящими. Далеко не каждая лаборатория имеет в своем распоряжении ТЭМ. По этой причине, в настоящее время метод ТЭМ используется в основном для разработки количественных стандартов. Другой метод количественного анализа ВНУПЦР-РВ (абсолютный вариант), сегодня широко распространен и считается приоритетным. Однако, этот метод сложен в исполнении и довольно затратен, так как требует применения международных количественных стандартов, которые разработаны лишь для небольшого числа вирусов и только для скрининга банков крови. Для рутинной вирусологической диагностики в фекальных пробах такие стандарты еще не разработаны [8]. Целью данного исследования явилась разработка упрощенного графического способа количественной оценки ВН в фекальных образцах с помощью калибровочного графика на основании имеющихся данных, полученных относительной ПЦР-РВ и с применением техники NanoDrop-спектрофотометрии, выбранной в качестве рабочего метода измерения, с подтверждением этих данных ТЭМ.

\section{Материалы и метолы}

В данной работе в качестве стандарта для построения графика был выбран клинический фекальный образец от ребенка с острой кишечной инфекцией, госпитализированного в один из инфекционных стационаров города Нижнего Новгорода. При выборе использовались данные о видовом составе и коэффициенте порогового цикла вирусов, обнаруженных в данном образце относительным вариантом количественной ПЦР, а также данные о концентрации вирусной НК в единице объема образца $\left(1 \mathrm{Mm}^{3}\right)$, измеренной методом NanoDrop-спектрофотометрии. Выбранный образец содержал ротавирусы, имел низкий коэффициент порогового цикла $\mathrm{Ct}=12,6$, свидетельствующий о высокой концентрации вируса.

\section{Выделение и очистка ротавирусных частиц из фекальной пробы}

Две порции (2 x 1,5 мл) 10\%-й фекальной суспензии, выбранной в качестве стандарта фекального образца в буфере для выделения (50 мМ трис-НC1, pH 8,0, 10 мМ $\mathrm{NaCl}$, 1,5 мM 2-меркаптоэтанол), гомогенизировали и осветляли низкоскоростным центрифугированием в угловом роторе центрифуги с охлаждением при 7000 об/ мин в течение 20 минут. При этом осаждался клеточный дебрис и бактериальная микрофлора. В надосадочной жидкости оставались частично очищенные вирусные частицы. От степени очистки вируса от примесей зависит точность измерения концентрации вирусной НК. Дальнейшую очистку вируса от примесей проводили методом осаждения вируса ультрацентрифугированием через 30\%-й раствор сахарозы [5, с275-276]; [13]. Вирус в буфере для выделения (1 мл) наслаивали на 1/5 объема GTN буфера (200мМ глицин, 50мМ трис-НC1, 100мМ $\mathrm{NaCl}, \mathrm{pH} 7,5)$, содержащего $30 \%$ сахарозы (сахарозную «подушку») и осаждали в течение 1 ч при 43000 об/мин на микроультрацентрифуге Sorvall MX-150 в угловом роторе S140-AT. Вирусные частицы проходили через слой 30\% -й сахарозы, а более легкие примеси (белки и т.д.) задерживались сахарозной «подушкой». После ультрацентрифугирования осадок с вирусом ресуспендировали в 0,1 мл деионизованной воды (1/10 часть от исходного объема). Для лучшего растворения осадка, его сначала вортексировали в течение 30 минут, затем выдерживали в течение 12 часов при $4^{\circ} \mathrm{C}$.

\section{Выделение РНК из сконцентрированных и очищенных вирусных частиц}

Нуклеиновую кислоту (НК) из очищенного вируса выделяли, модифицируя метод, предложенный Новиковой и др. [6]. К предварительно очищенному и сконцентрированному вирусу, растворенному в 0,1 мл воды, добавляли 0,03 мл экстрагирующего буфера $\left(0,03 \mathrm{M} \mathrm{CH}_{3} \mathrm{COONa}\right.$, $0,9 \mathrm{M} \mathrm{NaCl}, 0,012 \mathrm{M}$ EDTA, 3\% SDS). Смесь вортексировали и инкубировали в течение 10 минут при температуре $65^{\circ} \mathrm{C}$. После охлаждения при минус $4^{\circ} \mathrm{C}$ в течение 2 минут, смесь центрифугировали при 13 тыс об/мин в течение 10 минут. Супернатант отбирали в чистую пробирку 
Таблица 1. Результаты расчета ВН в разведениях стандартной пробы, полученные с помощью метода NanoDrop-спектрофотометрии

\begin{tabular}{|l|l|l|l|l|}
\hline \multicolumn{2}{|l}{ Значения ВН в 4-х десятикратных разведених стандарта } \\
$\begin{array}{l}\text { Номер } \\
\begin{array}{l}\text { десятикратного } \\
\text { разведения }\end{array}\end{array}$ & $\begin{array}{l}\text { Кратность } \\
\text { разведения } \\
\text { образца в воде }\end{array}$ & $\begin{array}{l}\text { Концентрация вирусной РНК } \\
\text { в разведении стандарта (нг/мкл) }\end{array}$ & $\begin{array}{l}\text { Концентрация } \\
\text { вирусной РНК } \\
\text { в разведении } \\
\text { стандарта (нг/1 мл) }\end{array}$ & $\begin{array}{l}\text { Предполагаемая } \\
\text { вирусная нагрузка } \\
\text { в 1мл стандарта }\end{array}$ \\
\hline 0 & 1 & 410,08 & 41008 & $1,93 \cdot 10^{12}$ \\
\hline 1 & $1 / 10$ & 41,34 & 4134 & $1,94 \cdot 10^{11}$ \\
\hline 2 & $1 / 10^{2}$ & 4,48 & 448 & $2,1 \cdot 10^{10}$ \\
\hline 3 & $1 / 10^{3}$ & 0,44 & 44 & $2,07 \cdot 10^{9}$ \\
\hline
\end{tabular}

Примечание: число частиц в 1 мл разведения стандарта соответствует их числу в 100 мкл концентрата

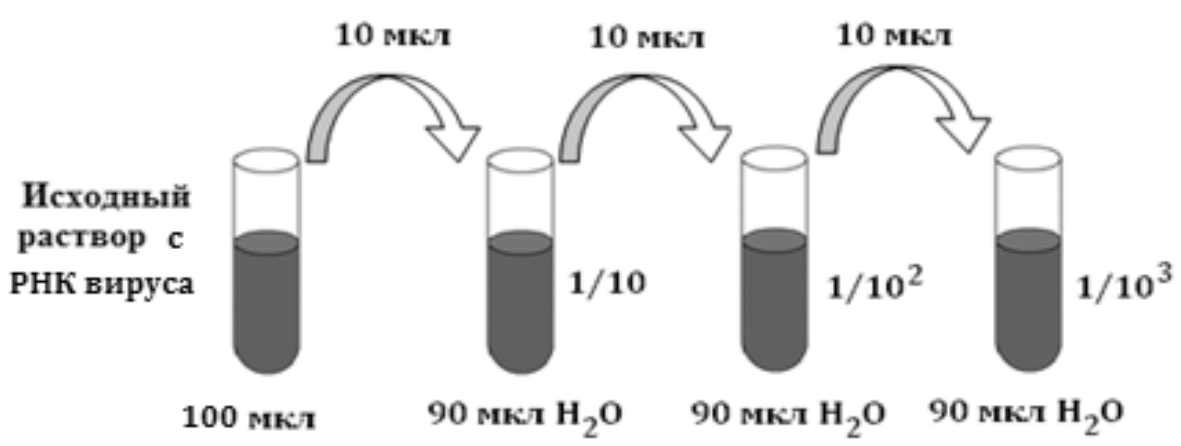

Рис. 1. Схема десятикратных разведений вирусной РНК в воде.

Эппендорф, содержащую 0,01 мл 3М ацетата натрия, $\mathrm{pH}$ 5,2. Добавляли 0,07 мл изопропанола и после вортексирования осаждали в центрифуге при 13тыс об/мин 10 минут. Жидкую фазу декантировали, к осадку с НК добавляли для промывки 70\%-й этанол (0,05 мл) и еще раз осаждали в том же режиме. Затем осадок с НК высушивали в термостате при $37^{\circ} \mathrm{C}$ в течение 20 минут и растворяли в 0,1 мл деионизованной воды.

\section{Результаты исслеАования}

При построении стандартной кривой использовали результаты измерения концентрации выделенной НК в пробе, взятой в качестве стандарта. Концентрацию вирусной HK определяли методом NanoDrop-спектрофотометрии. По концентрации вирусной НК (нг/мл) подсчитывали число единиц вирусного генома в 1 мл образца, соответствующее абсолютному значению $\mathrm{BH}$ и строили калибровочный график.

\section{Протокол измерения концентрации вирусной РНК в разведениях стандарта}

После выделения РНК из стандартной вирусной пробы, делали ряд десятикратных разведений выделенной
РНК. Для равномерного распределения РНК вируса перед очередным разведением проводили ультразвуковую обработку (рисунок 1). Далее определяли концентрацию РНК в разведениях (в нг/мл) с помощью метода NanoDrop-спектрофотометрии при длине волны 260 нм.

\section{Алгоритм определения вирусной нагрузки в пробе методом NanoDrop-спектрофотометрии}

По концентрации вирусной РНК рассчитывали ВН в разведениях пробы. Геном ротавируса состоит из 11 сегментов двунитевой РНК, размером от 667 до 3302 пар нуклеотидов, в общей сложности - из 18555 пар нуклеотидов (37110 нуклеотидов). Молекулярный вес (Мв) генома одной ротавирусной частицы определяли, исходя из того, что каждый нуклеотид имеет молекулярный вес 345 а.е.м. (атомных единиц массы или дальтон «Да»). Мв генома ротавируса $=37110 \cdot 345($ Да $)=12802950$ (Да) $\nabla$ $2.13 \cdot 10^{-8}$ нанограмм (нг). Перерасчет дальтон в нанограммы производили с применением онлайн калькулятора (https://calc.by/math-calculators/scientific-calculator. html). C помощью NanoDrop-спектрофотометра определяли концентрацию (в нг/мл) вирусной НК в разведении стандартной пробы. Далее, разделив ее на массу НК одной вирусной частицы, находили предполагаемую ВН 


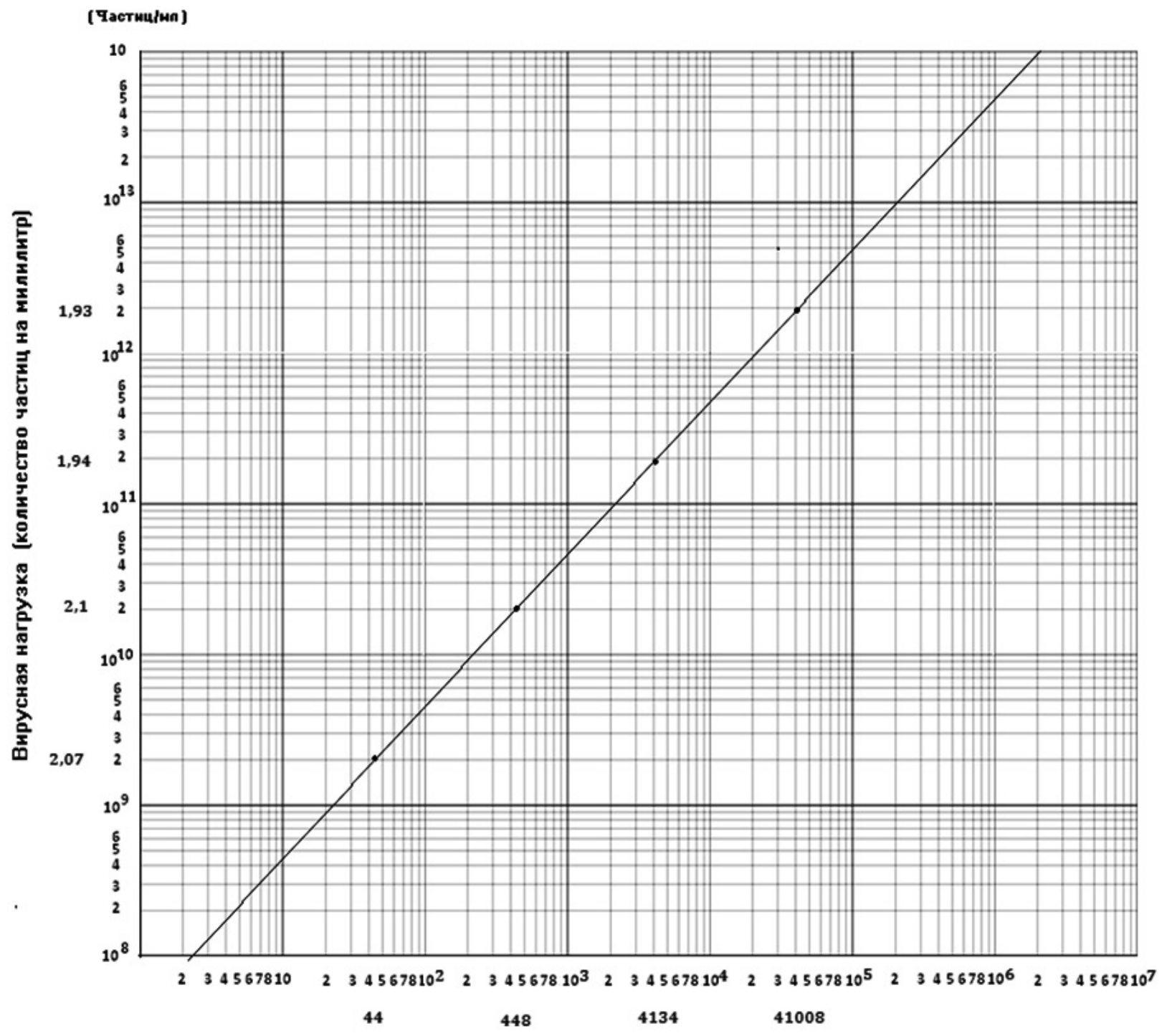

Концентрация вируснои́ нуклеиновои́ кислоты [нг/мл]

Рис. 2. График для определения ВН в интервале десятикратных разведений стандарта 1013-108 (ч-ц/мл).

(число вирусов в 1 мл разведения). Усредненные данные, полученные при измерении концентрации вирусной НК в 1 мл десятикратных разведений стандартной пробы методом NanoDrop-спектрофотометрии и соответствующие этой концентрации количества вирусных частиц, представлены в таблице 1.

\section{Алгоритм построения калибровочного графика «стандартной кривой»}

При построении калибровочной кривой, характеризующей вирусную нагрузку в разведениях стандарта, использовали значения концентрации вирусной НК (в нг/мл), измеренные спектрофотометрически и, соответствующее этим значениям количество вирусных частиц, подсчитанное аналитически (рисунок 2). При построении использовали значения концентрации НК, полученные для всего интервала десятикратных разведений. График построен в логарифмическом масштабе по двум осям, при котором представленная на графике зависимость имеет вид прямой линии, что облегчает анализ ВН. На оси «Х» этого графика откладывали в логарифмическом масштабе значения концентрации вирусной НК (в нг/мл), измеренной на спектрофотометре, а на оси «Ү» — количество вирусных частиц в разведении, соответствующее этой концентрации. Рассчитанное количество вирусных частиц в разведениях, отображенное на графике, было в дальнейшем валидировано с помощью электронной микроскопии. 
Таблица 2. Расчетные и реальные результаты измерений числа вирусных частиц в 1 мл десятикратных разведений стандартной пробы

\begin{tabular}{|c|c|c|c|c|c|c|}
\hline $\begin{array}{l}\text { Номер } \\
\text { разведения } \\
\text { образца }\end{array}$ & $\begin{array}{l}\text { Кратность } \\
\text { разведения } \\
\text { образца } \\
\text { в воде }\end{array}$ & $\begin{array}{l}\text { Число сфер } \\
\text { латекса в } 1 \\
\text { мл эталона }\end{array}$ & $\begin{array}{l}\text { Среднее число частиц } \\
\text { латекса, } \\
\text { наблюдаемое } \\
\text { на } 10 \text { полях при } \\
\text { увеличении } 12000 \\
\text { после } 5 \text { минут } \\
\text { адсорбции при } \\
\text { температуре } 25^{\circ} \mathrm{C}\end{array}$ & $\begin{array}{l}\text { Среднее число } \\
\text { вирусов, } \\
\text { наблюдаемое } \\
\text { на } 10 \text { полях при } \\
\text { увеличении } 12000 \\
\text { после } 5 \text { минут } \\
\text { адсорбции при } \\
\text { температуре } 25^{\circ} \mathrm{C} \\
\end{array}$ & $\begin{array}{l}\text { Расчетное число } \\
\text { вирусов в 1мл } \\
\text { разведения } \\
\text { стандарта, } \\
\text { по данным } \\
\text { измерения } \\
\text { (ч-ц/мл) }\end{array}$ & $\begin{array}{l}\text { Реальное число } \\
\text { вирусов в } 1 \text { мл } \\
\text { разведения } \\
\text { стандарта } \\
\text { подсчитанное } \\
\text { методом ТЭМ }\end{array}$ \\
\hline 0 & 1 & $2,7 \cdot 10^{12}$ & $\sim 150$ & $\sim 107$ & $1,93 \cdot 10^{12}$ & $\left(1,93 \cdot 10^{12}\right)$ \\
\hline 1 & $1 / 10$ & $2,7 \cdot 10^{11}$ & $\sim 16$ & $\sim 12$ & $1,94 \cdot 10^{11}$ & $\left(1,94 \cdot 10^{11}\right)$ \\
\hline 2 & $1 / 10^{2}$ & $2,7 \cdot 10^{10}$ & $\sim 2$ & $\sim 1,4$ & $2,1 \cdot 10^{10}$ & $\left(2,1 \cdot 10^{10}\right)$ \\
\hline 3 & $1 / 10^{3}$ & $2,7 \cdot 10^{9}$ & $\sim 0,3$ & $\sim 0,2$ & $2,07 \cdot 10^{9}$ & $\left(2,07 \cdot 10^{9}\right)$ \\
\hline
\end{tabular}

График отражает прямую зависимость концентрации вирусной НК в 1 мл разведения стандартной пробы от числа вирусных частиц в данном объеме. Вертикальная ось в логарифмическом масштабе показывает количество вируса в 1 мл разведения стандарта, а горизонтальная -концентрацию НК вируса в этом объеме.

\section{Подсчет вирусов в стандартной пробе методом ТЭМ}

Достоверность значений ВН в разведениях стандартной пробы, определенных с помощью метода NanoDrop-спектрофотометрии, в дальнейшем была подтверждена корреляцией с результатами, полученными ТЭМ. Для этого проводили серию десятикратных разведений сконцентрированного вируса по той же схеме, по которой разводили его РНК (рисунок 1). Подсчет вирусов в стандартной пробе осуществляли с помощью техники «Loop drop» (Мейхи 1988). В работе использовали стандарт из водной дисперсии однородных полистирольных латексных шариков «микросфер» с диаметром частиц 0,07 мкм (серия МД4, производства ООО «НЦ» «Ленхром») в концентрации $2,7 \cdot 10^{14}$ частиц в $1 \mathrm{~cm}^{3}$.

B соответствии с техникой «Loop drop», брали 3 мкл пробы, выбранной в качестве стандарта и, после предварительной ультразвуковой обработки, смешивали с равным объемом латексных микросфер (имитирующих вирус) с известным числом в единице объема (1 мл). Смесь в виде капли наносили на электронно-микроскопическую сетку с решеткой 200 меш с парлодиевой подложкой. После экспозиции в течение 5 минут, сетку прополаскивали в деионизованной воде (2-5 сек) и контрастировали 3\%-й фосфорно-вольфрамовой кислотой, $\mathrm{pH}$ 6,8, в течение 60 сек. Далее препарат подсушивали на воздухе и просматривали в ТЭМ, подсчитывая среднее количество вирусных частиц и латексных микросфер на 10 полях разных ячеек сеточки. Сравнивая число шариков латекса с известной концентрацией с числом вирусных частиц в одних и тех же полях, подсчитывали концентрацию вирусных частиц.

\section{Алгоритм подсчета частиц в стандартной пробе на примере разведения № 0}

В разведении № 0 в 1 мл содержится по расчету 2,7·10 12 частиц латекса (калибратор, разведенный в 100 раз). Микрокапля объемом 6 мкл для нанесения на подложку сеточки с целью подсчета ВН в электронном микроскопе формируется из 3-х мкл водной суспензии латекса и 3-х мкл водной суспензии вируса. По соотношению частиц калибратора и вируса, подсчитанных в поле микроскопа (при увеличении 12000 крат), рассчитывали реальное значение ВН в разведении образца, взятого в качестве стандарта, и сравнивали с расчетным значением. Результаты контрольного подсчета количества вирусов в десятикратных разведениях стандарта, полученные с помощью техники «Loop drop» в подтверждение спектрофотометрическим данным, представлены в таблице 2.

Электронная микрофотография участка электронно-микроскопической сеточки с вирусными частицами, по которому определялась BH методом «Loop drop» в нyлевом разведении пробы, взятой в качестве стандарта, представлена на рисунке 3.

На электронограмме представлен один из десяти участков просмотра в электронном микроскопе с расположенными на нем ротавирусами и частицами латекса. Среднее число вирусных частиц на этих участках при увеличении 12000 составило 107, что равно 1,4 (или $71 \%)$ от количества частиц калибратора ( 150). Следовательно, если в 1 мл калибратора содержится 2,7·10 12 частиц, то в 1 мл исходной вирусной суспензии содержится $1,93 \cdot 10^{12}$ вирусов. Это количество соответствует величине ВН, вычисленной по концентрации НК, измеренной методом NanoDrop-спектрофотометрии и определенной по графику. 


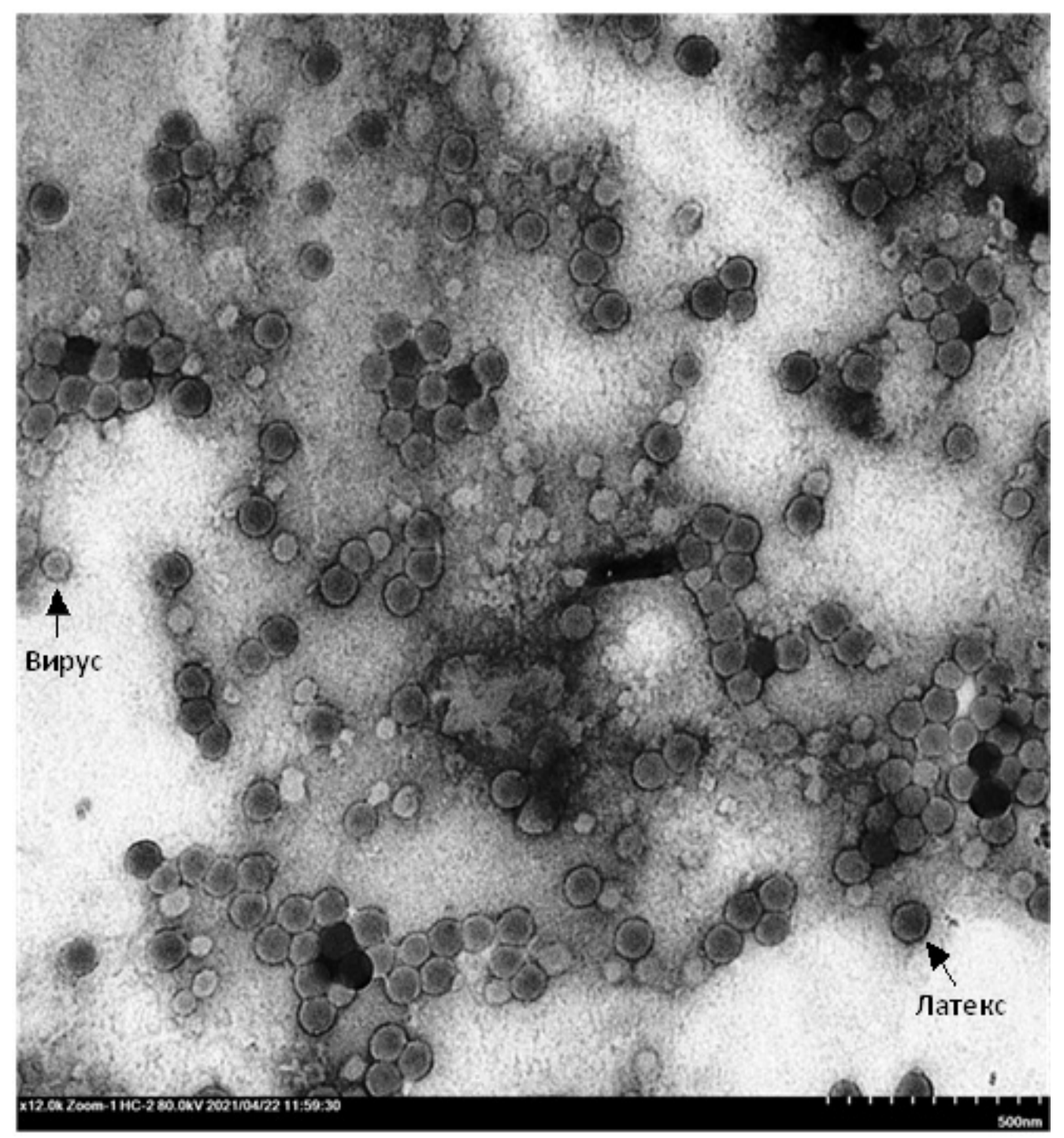

Рис. 3. Электронограмма одного из 10 участков просмотра в электронном микроскопе препарата с ротавирусами, приготовленного из нулевого десятикратного разведения вирусного образца, взятого в качестве стандарта.

\section{Обсужление}

Методы определения количества вируса, в основе которых лежат его биологические свойства (способность размножаться в культуре клеток, куриных эмбрионах или агглютинировать эритроциты), не пригодны для определения числа вирусных частиц, поскольку соотношение между единицами гемагглютинации или инфекционности и числом вирусных частиц в значительной степени зависит от штамма вируса [5, с.181]. При количественном анализе ВН предпочтительным для исследователей является абсолютное ее определение, позволяющее не просто сравнить два или несколько образцов в одном эксперименте по величине ВН (относительный вариант количественной ПЦР-РВ), а измерить в единицах количество вирусов в этих образцах. Самым распространенным и испытанным методом, используемым при создании количественных стандартов для подсчета вирусных частиц, является электронно-микроскопическая техника «Loop drop», разработанная еще во 2-й половине 20-го века в [5, с. 181, 275]. Однако, подсчет вирусных частиц по технике «Loop drop» с помощью количественных калибраторов (частиц латекса) утомителен, так как требует немалого визуального напряжения исследователя и поэтому в качестве рутинного способа измерения вирусной нагрузки этот метод редко применяли [8].

Не всегда доступен и абсолютный вариант ПЦР-РВ для количественной характеристики ВН в клинических 
образцах. По этой причине при анализе ВН в фекалиях часто используется относительный способ ПЦР диагностики. Однако, показатель порогового цикла Ct в относительном количественном анализе методом ПЦР-РВ в отсутствии количественного стандарта дает лишь сравнительную характеристику концентрации вируса в образцах клинического материала, а количественное определение ВН требует прежде всего абсолютного определения, которое выражает количество вируса в частицах на 1 мл исследуемого образца.

Это послужило предпосылкой разработки упрощенного способа количественной характеристики ВН в вируссодержащих образцах. Поскольку самым адекватным стандартом для определения ВН принято считать ЖВК [8, с. 172, 174], количественный стандарт для рутинной диагностики ВН в фекалиях, можно создать самим из тех же обычных инфекционных образцов, идентичных исследуемым. Вирусную нагрузку в них можно определить по концентрации НК в пробе, выбранной в качестве стандарта. Зная массу одного вирусного генома в образце, можно суммарное их количество перевести в число вирусных частиц. Затем, построив график линейной зависимости концентрации НК в единичном объеме стандартного образца от количества вирусных частиц в нем, соответствующего этой концентрации, определить ВН в образце.

Графический способ предназначен для исследования ВН в клинических образцах, проанализированных на присутствие кишечных вирусов методом относительного количественного анализа ПЦР-РВ. Точность оценки величины ВН в данном способе напрямую зависит от чистоты выделенной вирусной НК, концентрация которой измеряется методом NanoDrop-спектрофотометрии, поэтому вирусный препарат, подлежащий количественной оценке, должен содержать очень низкий уровень не принадлежащих данному вирусу нуклеиновых кислот. С этой целью использовали метод ультрацентрифугирования, предусматривающий удовлетворительную очистку вирусного препарата от инородных частиц при его прохождении через сахарозную подушку [5, с. 98]; [13].

Поскольку в графическом способе количество вируса в клиническом образце определяется по стандарту одного вида с ним, количественная оценка ВН в образцах по калибровочному графику производится отдельно для каждого вида вирусов. Необходимость отдельных стандартных графиков для количественной оценки ВН каждого вида вирусов вызвана тем, что построение этих графиков основано не только на прямой зависимости количества вируса от концентрации его генома в образце, но и от величины генома, которая у разных видов отличается. В данной работе представлен упрощенный вариант графической методологии оценки ВН в образце, проанализированном относительным вариантом ПЦР-РВ. Он рассчитан на подсчет ВН в образце, содержащем только один вид вируса (на примере ротавируса). Однако данная методология может быть использована и для подсчета ВН для нескольких видов кишечных вирусов, одновременно присутствующих в фекальном образце.

По стандартному графику можно определить ВН и при микст-инфекции, когда в пробе присутствуют вирусы другого вида и количественное соотношение между ними известно. По концентрации вирусной НК, полученной относительными методами анализа, можно рассчитать массовую долю генома, приходящуюся на вирусы каждого вида в 1 мл образца с микст-инфекцией и рассчитать число этих вирусов или найти по графику.

Для подтверждения достоверности вычисленного по концентрации вирусной НК количества вирусных частиц в разведениях стандартной пробы, использовали ТЭМ. По данным, представленным в таблице 2, видно, что в целом результаты подсчета вирусной нагрузки методом NanoDrop-спектрофотометрии близки по значению с результатами, полученными подсчетом в электронном микроскопе (среднее число вирусных частиц на ячейку электронно-микроскопической сеточки, представленное в таблице, коррелирует с концентрацией РНК в пробе). С повышением содержания РНК в милилитре пробы, пропорционально растет и число вирусных частиц в поле ячейки микроскопа. Корреляция полученных результатов эксперимента позволяет констатировать их достоверность и возможность применения графического способа для количественного анализа ВН в клинических образцах.

\section{Зак^ючение}

Точная количественная характеристика ВН в клинических образцах, особенно в фекалиях, являющихся нестандартизованным материалом, относительными методами не возможна. При подсчете ВН в пробах приоритет отдается абсолютным вариантам количественных методов, способных выразить ВН в числе вирусных единиц на единицу объема пробы. Такие методы, даже если они не обладают высокой точностью, позволяют дать абсолютный количественный результат. Однако отметим, что распространенный сегодня для количественной оценки ВН абсолютный вариант метода Real-time PCR, достаточно сложен, дорог и не всегда доступен для лабораторий, поскольку требует наличия соответствующих количественных стандартов. В данной работе предложен графический способ количественного анализа ВН в клинических пробах по определяемой методом спектрофотометрии концентрации вирусной НК (нг/мл). 
Определение ВН по стандартной кривой представляется доступным способом ее количественного анализа в клинических образцах с известным видовым спектром и количественным соотношением вирусов, при условии, что данные образцы проанализированы ранее относительным вариантом ПЦР «в реальном времени». Поставленная в исследовании задача определения ВН по графику с привлечением NanoDrop-спектрофотометрии в качестве рабочего метода анализа, а также техники ТЭМ в качестве метода контроля, была решена. Была доказана корреляция концентрации вирусной нуклеиновой кислоты, содержащейся в единице объема пробы, с количеством вирусных частиц в ней.
На основе доказанной корреляции построен стандартный график, который позволит осуществить анализ ВН в пробах графическим способом, заменив технику количественной ПЦР в абсолютном варианте менее сложной для исследователя NanoDrop-спектрофотометрией. Достоверность и простота оценки ВН по стандартному графику на основании концентрации НК, определяемой с помощью спектрофотометрических приборов (NanoDrop-спектрофотометры, флуориметры), свидетельствует о целесообразности применения данной технологии для приблизительного количественного определения ВН даже в пробах с содержанием вируса ниже $10^{8}$ частиц/мл при условии их предварительного концентрирования.

\section{ЛИТЕРАТУРА}

1. Антонова О.С., Рудницкая Г.Е., Тупик А.Н., Буляница А.Л., Евстрапов А.А., Курочкин В.Е. Полимеразная цепная реакция: приборная и методическая реализация. Обзор аналитических характеристик (0бзор). Научное приборостроение, 2011, том 21, № 4, с. 5-21.

2. Белов Ю.В., Петров А.И., Лавров В.В., Курочкин В.Е. Особенности количественных измерений содержания нуклеиновых кислот методом полимеразной цепной реакции в реальном времени. Научное приборостроение, 2011; 21(1): 44-49.

3. Зайцев Б.Н., Таранов 0.С., Рудометова Н.Б., Щербакова Н.С., Ильичев А.А., Карпенко Л.И. . Оптимизированный метод подсчета количества вирусных частиц с помощью электронной микроскопии. Вавиловский журнал генетики и селекции. Том 23, № 3 (2019). С. 337-342.

4. Кашников А.Ю. Особенности пробоподготовки для электронно- микроскопическго исследования кишечных вирусов. Современная наука: Актуальные проблемы теории и практики. Серия: Естественные и технические науки. 2018; № 8. С. 35-42.

5. Мейхи Б. Вирусология. Методы. 1988; Москва. «Мир». С. 275-276.

6. Новикова Н.А., Епифанова Н.В., Романова Т.В., Макеева Л.В., Животовский М.В. Ротавирусный гастроэнтерит. Противоэпидемические мероприятия. Пособие для врачей. Нижний Новгород, 1999. $20 \mathrm{C}$

7. Петрова И.Д., Зайцев Б.Н., Таранов О.С. Концентрирование вирусов и электронная микроскопия. Обзор. Генетика микроорганизмов. Вавиловский журнал генетики и селекции. 2020;24(3):276-283. D0I 10.18699/VJ20.620

8. Ребриков Д.В., Саматов Г.А., Трофимов Д.Ю. ПцР в реальном времени. Лаборатория знаний. 2018.

9. Строганова И.Я., Трухоненко А.А. Использование в вирусологии культуры клеток. Методические указания. Красноярск 2013; 48 с.

10. Beniac D.R., Siemens C.G., Wright C.J., Booth T.F. A filtration based technique for simultaneous SEM and TEM sample preparation for the rapid detection of pathogens. Viruses. 2014;6: 3458-3471. DOI 10.3390/v6093458.

11. https://calc.by/math-calculators/scientific-calculator.html

12. Malenovska H. Virus quantitation by transmission electron microscopy, TCID50, and the role of timing virus harvesting: a case study of three animal viruses. J. Virol. Methods. 2013; 191(2):136-140. D0I 10.1016/j.jviromet.2013.04.008.

13. Nakagomi 0. Fundamentals of Ultracentrifugal Virus Purification. 2020. Schutten M., van den Hoogen B., van der Ende M.E., Gruters R.A., osterhaus A.D., Niesters H.G. Development of a real-time quantitative RT-PCR for the detection jf HIV-2 RNA in plasma // JVirol Methods., 2000, 88:81-87.

14. Williams R.C. Electron Microscopy of Viruses. Advances in Virus Research. 2008. Vol. 2, 1954, P. 183-239. https://doi.org/10.1016/S0065-3527(08)60533-3

( К Кашников Александр Юрьевич ( a.kashn@yandex.ru ).

Журнал «Современная наука: актуальные проблемы теории и практики» 